\title{
New Evaluation Method of the Ability of Forming Fracture Network in Tight Sandstone Reservoir
}

\author{
Xin Lei, Shicheng Zhang, Tiankui Guo, and Bo Xiao
}

\begin{abstract}
Property of generating fracture network is the major factor that influences economical and effective exploitation of tight sandstone reservoir. Besides horizontal stress contrast, rock brittleness and natural fracture property are significant factors that affect fracture network extension. By using a new evaluation method of creating fracture network, the complexity of fracture network for tight sandstone cores and shale gas cores were compared after fracturing experiments. This method uses Soundless Cracking Agent (SCA) which could apply continuous expansion force to create fracture network in cores. It also combines with acoustic emission instrument to monitor the fracture propagation pattern. The experimental result shows that one simple planar fracture pattern was likely to be formed in tight sandstone cores, while one complex fracture without dominant fracture was more likely to be created in shale cores. Rock brittleness is not the significant factor that influences fracture network creation for tight sandstone reservoir. This method is a easy and reliable way to evaluate ability of forming fracture network in tight sandstone reservoir after hydraulic fracturing. It also shows the difference of fracture network generation mechanism between shale gas reservoir and tight sandstone reservoir.
\end{abstract}

Index Terms-Acoustic emission, brittleness, fracture network evaluation, tight sand reservoir.

\section{INTRODUCTION}

At present, tight oil is another hot spot in exploration and exploitation of unconventional reservoirs after shale gas. The United States attaches great importance to the exploration and development of tight oil reservoir, and try to copy the shale gas development mode. The development of tight oil in China starts late and the concept of tight oil has been widely accepted and used in recent years. According to the latest resource evaluation, reserve of tight oil resources is about12 billion tons in China.

"Volume fracturing" [1] is copied from shale gas development pattern and is the primary exploitation technology in tight oil reservoir to realize the commercial development currently. The main mechanism is to open natural fractures and expand them until shear sliding is occurred in the process of hydraulic fracturing. So it becomes important to understand the mechanism of fracture extension in tight sandstone. A large number of researchers study the

Manuscript received November 5, 2014; revised December 25, 2014.

Xin Lei, Shicheng Zhang, Bo Xiao are with the College of Petroleum Engineering, China University of Petroleum, Beijing 102249, China (e-mail: lei_beck@hotmail.com, zhangsc@cup.edu.cn, cupvip@sina.com).

Tiankui Guo is with the College of Petroleum Engineering, China University of Petroleum, Huadong 266580, China (e-mail: guotiankui@126.com). interaction of hydro-fractures and natural fractures through indoor fracturing simulation experiments to analyze the form and complexity of the fracture network [2]-[10]. However, the traditional indoor fracture network evaluation experiment requires large size rock cube for the triaxial test system. Not only the experiment is complex, but also the rock cube must be big size (more than $30 \mathrm{~cm}^{3}$ ) outcrop, which is cumbersome and hard to get. This new experimental method just uses $10 \mathrm{~cm}$ diameter core of target reservoir and takes no account of horizontal stress contrast. Soundless cracking agent is used to simulate hydraulic fracturing process. Acoustic emission technology is also combined to monitor crack propagation and evaluate the network forming ability.

\section{Physical and Mechanical ChaRacteristics of Rock}

\section{A. Brittleness Index}

There are three primary methods to evaluate rock brittleness index. First is mineralogical method [11]. The formula is brittleness index $(\%)=$ quartz content/ $($ quartz + carbonatite + clay mineral) content; Second method [12] relates with rock Young's modulus and Poison's ratio (1). When BRIT (brittleness) $>40$, rock is brittle. When BRIT $>60$, rock is strong brittle; the third method [13] uses uniaxial compressive strength and uniaxial extension strength (2) to calculate rock brittleness index. Table I represents the level of rock brittleness.

$$
\begin{gathered}
\text { YM_BRIT }=\left(\left(\mathrm{YMS} \_C-1\right) /(8-1)\right) \times 100 \\
\text { PR_BIRT }=\left(\left(\mathrm{PR} \_C-0.4\right) /(0.15-0.4)\right) \times 100 \\
\text { BRIT }=\left(\mathrm{YM} \_B R I T+P R \_B R I T\right) / 2
\end{gathered}
$$

$$
\mathrm{BI}=\sigma_{c} / \sigma_{t}
$$

Table II shows the average content of quartz and feldspar in tight sandstone cores are $49 \%$ and $18 \%$ more than shale cores which are $40 \%$ and $5.6 \%$. However, the clay mineral content of shale is $41.3 \%$ which is much more than tight sandstone's $16.5 \%$. The content of quartz and clay mineral will affect brittleness index.

\begin{tabular}{ccc} 
TABLE I: HIERARCHICAL CLASSIFICATION OF ROCK BRITTLENESS \\
\hline \hline Level & BI & Characteristic \\
\hline 1 & $>25$ & High Brittle \\
2 & $15<\mathrm{BI}<25$ & Brittle \\
3 & $10<\mathrm{BI}<15$ & Mediocre Brittle \\
4 & $\mathrm{BI}<10$ & Low Brittle \\
\hline \hline
\end{tabular}


TABLE II: ROCK MINERAL COMPOSITION OF DIFFERENT CORES

\begin{tabular}{|c|c|c|c|c|c|c|c|c|}
\hline \multirow{2}{*}{ Rock } & \multicolumn{7}{|c|}{ Mineral Composition and Content $(\%)$} & \multirow{2}{*}{$\begin{array}{c}\text { Clay } \\
\text { Mineral } \\
\text { Content } \\
(\%)\end{array}$} \\
\hline & Quartz & Orthoclase & Sodaclase & Calcspar & Dolomite & Siderite & Laumontite & \\
\hline $\begin{array}{l}\text { \#1 Tight } \\
\text { Sandstone }\end{array}$ & 49.5 & 12.8 & 9.3 & 1.3 & 8.1 & 3.2 & - & 15.8 \\
\hline $\begin{array}{l}\text { \#2 Tight } \\
\text { Sandstone }\end{array}$ & 48.4 & 3.9 & 10 & 5.8 & 12 & 1.6 & - & 18.3 \\
\hline \#3 Shale & 39 & 0.5 & 5 & 6.9 & 5.9 & - & - & 42.7 \\
\hline \#4 Shale & 41.3 & 0.4 & 5.3 & 6.3 & 6.8 & - & - & 39.9 \\
\hline
\end{tabular}

TABLE III: ROCK MECHANICAL PARAMETERS AND BRITTLENESS EVALUATION OF DIFFERENT ROCKS

\begin{tabular}{|c|c|c|c|c|c|c|}
\hline Rock & $\begin{array}{c}\text { Young's } \\
\text { Modulus /GMPa }\end{array}$ & $\begin{array}{l}\text { Poison's } \\
\text { Ratio }\end{array}$ & $\begin{array}{c}\text { Uniaxial Compressive } \\
\text { Strength/MPa }\end{array}$ & $\begin{array}{c}\text { Uniaxial Extension } \\
\text { Strength/Mpa }\end{array}$ & BRIT & BI \\
\hline \#1 Tight Sandstone & 21.7 & 0.132 & 82.2 & 4.1 & 42.0 & 20.3 \\
\hline \#2 Tight Sandstone & 20.4 & 0.137 & 83.8 & 4.3 & 40.0 & 19.6 \\
\hline \#3 Shale & 25.2 & 0.226 & 78.2 & 4.1 & 45.7 & 19.1 \\
\hline \#4 Shale & 26.9 & 0.234 & 78.6 & 3.9 & 45.3 & 20.2 \\
\hline
\end{tabular}

Table III represents the rock mechanical parameters of tight sandstone and shale cores. The Young's modulus and Poison's ratio of shale are more than tight sandstone. The BRITs of shale cores are slightly more than sandstone (1). The uniaxial compressive strength and uniaxial extension strength of shale cores and tight sandstone cores are almost the same which means the BIs are same (2). The result shows that brittleness indexes of four cores are basically identical.
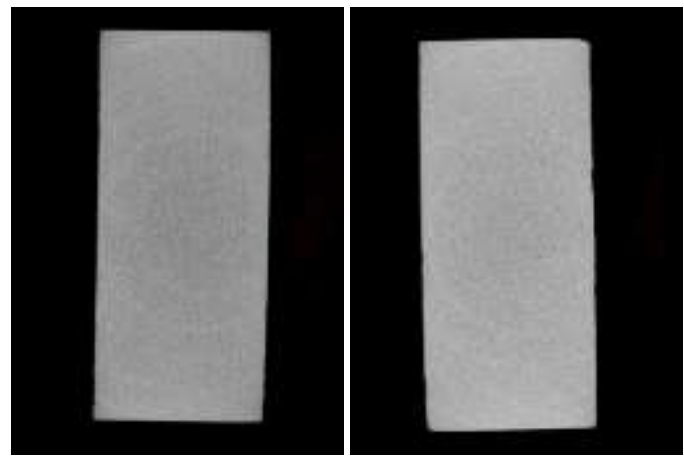

(a) CT scanning image of \#1 tight sandstone core (scanning angle, left: $0^{\circ}$, right: $90^{\circ}$ )

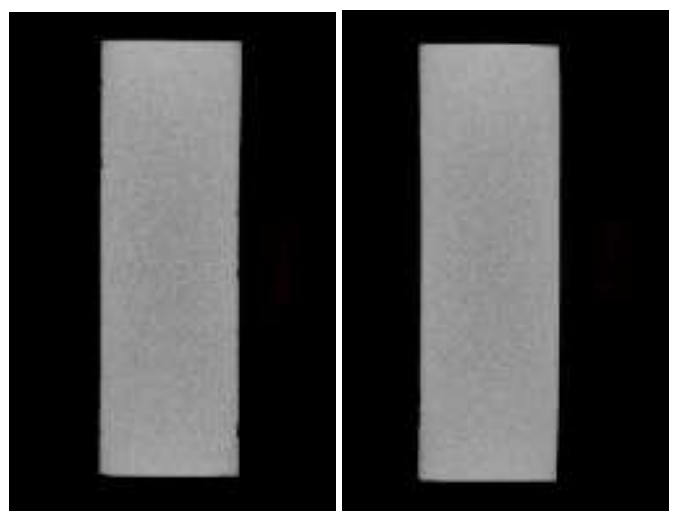

(b) CT scanning image of \#2 tight sandstone core (scanning angle, left: $0^{\circ}$, right: $90^{\circ}$ )

Fig. 1. CT scanning image of \#1 and \#2 tight sandstone cores.

\section{B. $\quad$ Natural Fracture Property}

Natural fracture property is another major factor that will influence the fracture network form. Before the experiment, the natural fracture characteristics of two tight sandstone cores are detected by using CT scan (Fig. 1).

Fig. 1 shows no natural fractures exist in \#1 and \#2 tight sandstone cores. Therefore, this evaluation experiment will focus on generating of fracture network which is affected by rock brittleness and mineral composition.

\section{EVALUATION EXPERIMENT}

This experimental evaluation method could simply and safely create fracture network in cores by using Soundless Cracking Agent (SCA). Compared with the traditional hydro-fracturing simulation experiment, SCA could apply continuous expansion force. Even if the creating fracture reaches to the surface of core, it still could keep the pressure and generate new fractures. Meanwhile, sound emission instrument will be connected with the core to monitor the whole process of forming fracture. For getting more reliable fracture shape, the core will be put in an iron tube and compacted by cement. It will make sure the core will bear ambient pressure which is provided by expansion force of SCA.

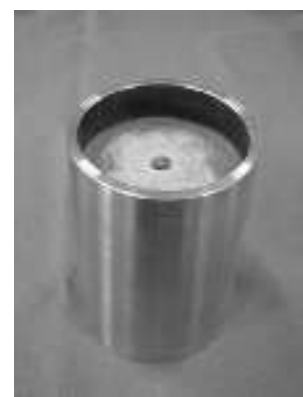

Fig. 2. Compaction grouting of cement slurry into annular space between core and iron tube.

\section{A. Experimental Instruments and Materials}

Experimental instruments: Iron tube (Self-made, inner 
diameter is $124.3 \mathrm{~mm}$, external diameter is $138.5 \mathrm{~mm}$, height is 200mm); PCI-II model acoustic emission system (made by Physical Acoustics Corp).

Experimental materials: Soundless Cracking Agent (SCA), cement, shale and tight sandstone cores (column diameter is $100 \mathrm{~mm}$, height is $100 \mathrm{~mm})$, butter.

\section{B. Experimental Procedure}

1) In order to take out the core easily after the experiment, butter should be spread equably on surface of cores and internal surface of iron tube;

2) Fill the annular space between core and iron tube with cement slurry. Make sure proportion of water and cement is the same in all experiments;

3) Wait until the cement solidifies, then drill a hole which diameter is $15 \mathrm{~mm}$ in the center of core (Fig. 2). The hole should be drill through the core for observing the fracture form conveniently;

4) Put 12 acoustic emission reception probes around the iron tube in form of 3 lines and 6 columns. This arrangement form is good for accurate positioning of acoustic emission system (Fig. 3);

5) Pour water into SCA, stir equably and fill into the hole. Run the acoustic emission system to monitor the process of fracture crack;

6) After the experiment, analyze the result and take out the core to observe the form of fracture.

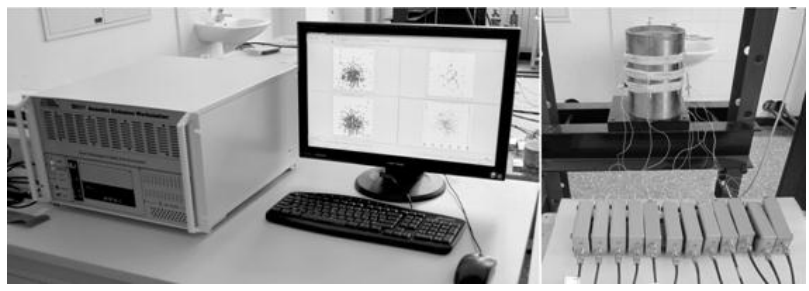

Fig. 3. Acoustic emission system and arrangement of probes position.

\section{Experimental Results and Analysis}

\section{1) \#1 tight sandstone core}

During the experimentation of \#1 tight sandstone core, 13533 acoustic emission events are receipted by the system. Fig. 4 represents the change of acoustic emission events. It shows the first fracture begins to crack at 800 seconds. Cracking direction is from location between No.1 and No.3 probes to location between No.7 and No.9 probes $\left(45^{\circ}\right.$ to $225^{\circ}$ ). After 2360 seconds, a major fracture is formed. From 5322 seconds, another major fracture starts to form in vertical direction of the first fracture. In the end, two fractures that perpendicular to one another are formed.

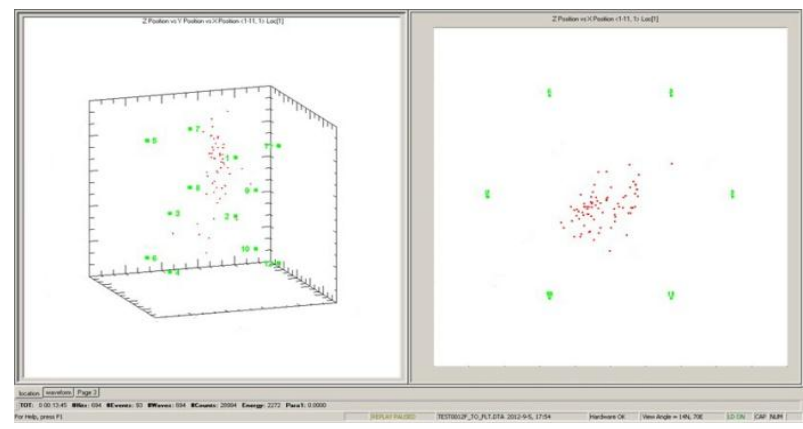

(a) Acoustic emission location map after 825 seconds

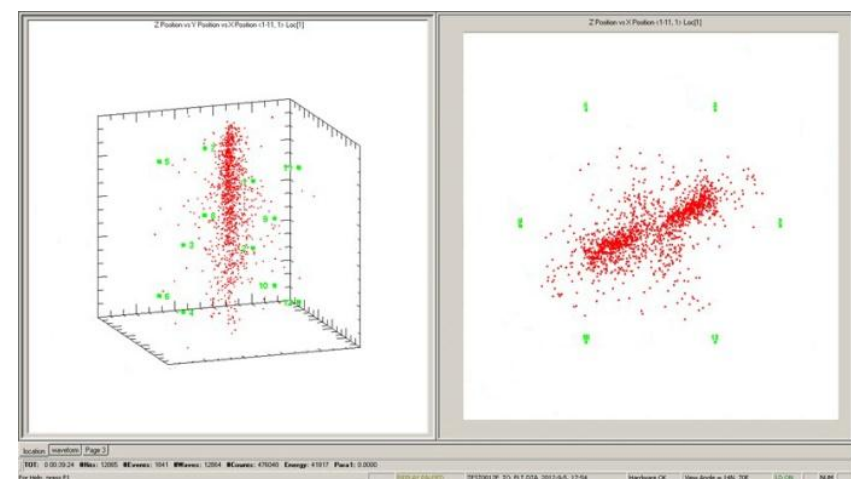

(b) Acoustic emission location map after 2364 seconds

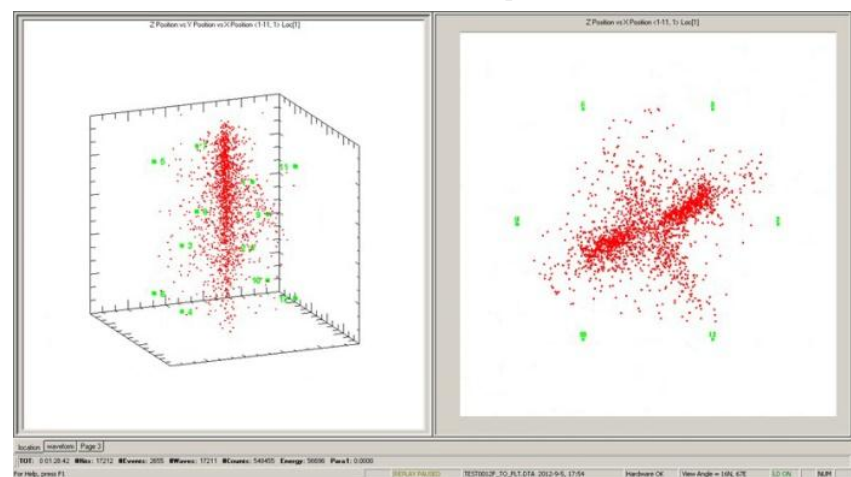

(c) Acoustic emission location map after 5322 seconds

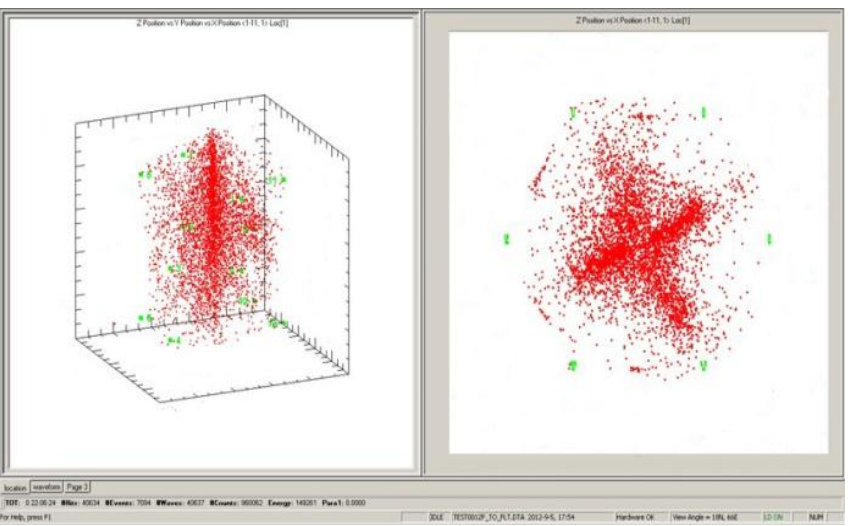

(d) Acoustic emission location map after 79583 seconds

Fig. 4. Acoustic emission location maps at different times for \#1 tight sandstone core.

Take out the \#1 tight sandstone core, it could be observed clearly that the whole core is separated by two major fractures (Fig. 5). Open the core along with the fracture, no other branch fractures or micro fractures are found.

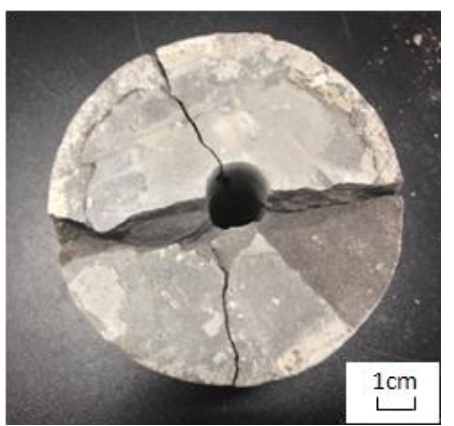

Fig. 5. Fractures state of \#1 tight sandstone surface after fracturing by soundless cracking agent.

2) \#2 tight sandstone core

Compared with \#1 tight sandstone core, the experiment of \#2 tight sandstone core only receives 9906 acoustic emission 
events. Fig. 6 shows this core forms two major factures as same as \#1 core. Direction of a fracture is from 30 degree to 210 degree. Another is from 150 degree to 330 degree. Fig. 7 represents the acoustic emission events location of fractures is similar with actual fractures form.

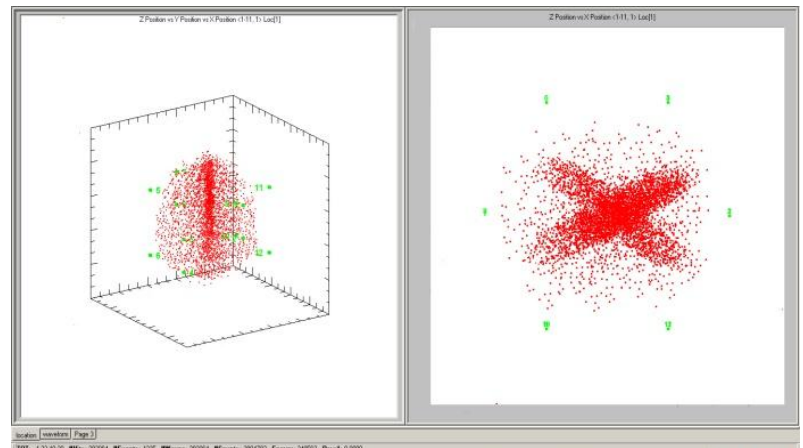

Fig. 6. Final acoustic emission location map for \#2 tight sandstone core

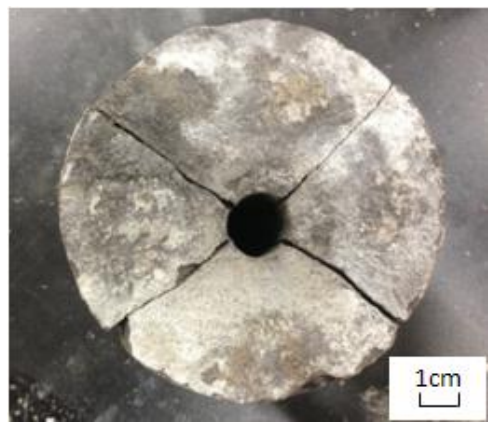

Fig. 7. Fractures state of $\# 2$ tight sandstone surface after fracturing by soundless cracking agent.

3) \#3 and \#4 shale cores

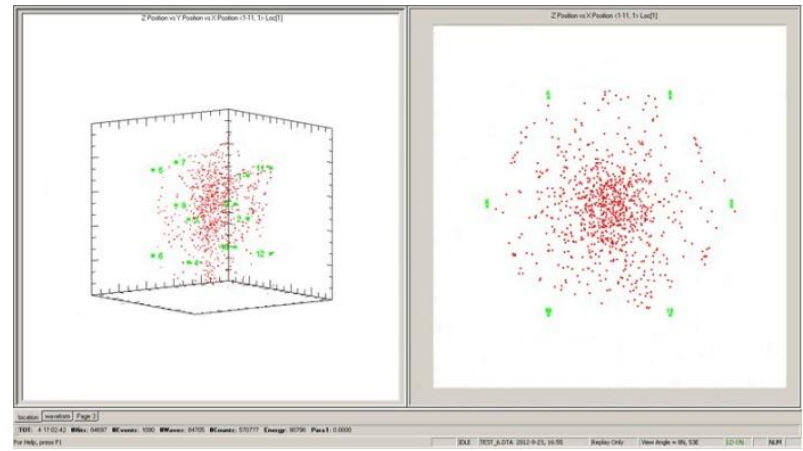

Fig. 8. Final acoustic emission location map for the \#3 shale core.

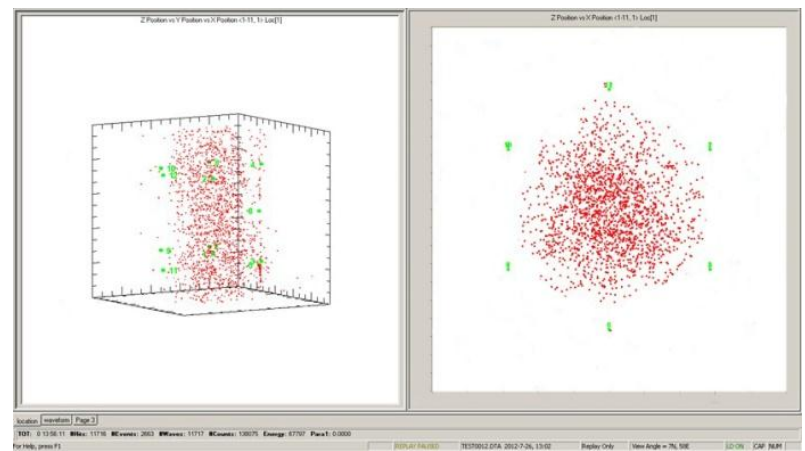

Fig. 9. Final acoustic emission location map for the \#4 shale core.

The acoustic emission event of \#3 and \#4 shale cores are 1090 and 3567. Fig. 8 and Fig. 9 final acoustic emission location maps show that events present random distribution and no major fractures. Fig. 10 represents complex fracture form on surface of shale cores after experiment.

4) Comparison of tight sandstone cores and shale cores

According to above experimental results, the number of acoustic emission event of tight sandstone cores is much more than shale cores. It shows the more clay content is and less quartz content is, the less acoustic emission events are. Because quartz content of tight sandstone is more than shale. The process of fracture forming is breakage between quartz granules and crystalline structures. Tight sandstone could provide higher acoustic emission energy than shale.

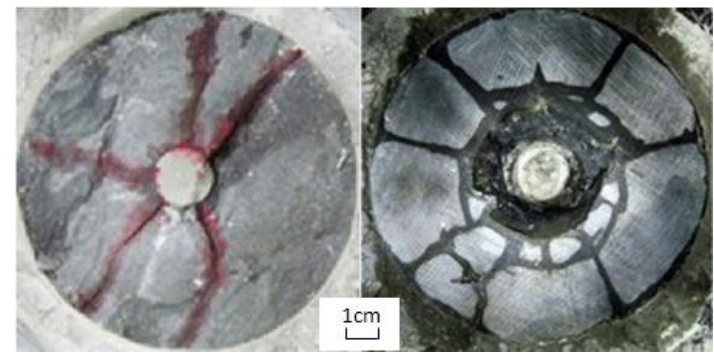

Fig. 10. Fractures state of shale cores surface after fracturing by soundless cracking agent.

(Left: \#3, Right: \#4)

On the other hand, natural fractures and settled layers of shale are more developed than tight sandstone, and anisotropy is stronger. Therefore, acoustic emission energy will reduce during the transfer process. Also fractures will extend along with natural fractures and settled layers which contain clay-cement mainly. Thus, acoustic emission energy is very low and hardly received. As a result, fractures in tight sandstone could produce more acoustic emission event than in shale.

\section{CONCLUSION}

AE location results show that it has a good correlation between AE location maps and the fracture morphology on the surface of the core. Tight sandstones with low clay content $(<20 \%)$ have more acoustic emission events, and AE events distribute along with main fractures. Simple plane fracture characteristics are displayed after treatment. Acoustic emission quantity of shale is less than tight sandstone and scattered randomly. No main fractures characteristics are displayed.

Under the condition of same brittleness index, none horizontal stress contrast and none natural fractures, Chang 7 tight sandstone cores didn't create fractures as complex as shale. Thereby brittleness index is not the main factor that influences fracture network form in tight sandstone. Due to shale containing sediments bedding, it can form complex fracture network even if the brittleness in not very high.

Under the condition of none or low horizontal stress contrast, Chang 7 tight sandstone cores can form a certain degree of complex fractures (symmetric four-way cracks).It shows volume fracturing technology has a certain effect to tight sandstone reservoir.

Besides horizontal stress contrast, natural fracture property is key factor affect fracture network forming of volume fracturing in Chang 7 tight sandstone reservoir. 


\section{NOMENCLATURE}

YMS_C $=$ static Young's modulus, $104 \mathrm{MPa}$

PR_C $=$ static Poison's ratio

$\sigma_{c}=$ uniaxial compressive strength, $\mathrm{MPa}$

$\sigma_{t}=$ uniaxial extension strength, $\mathrm{MPa}$

\section{REFERENCES}

[1] C. L. Cipolla, N. R. Warpinski, and M. J. Mayerhofer, "The relationship between fracture complexity, reservoir properities, and fracture-treatment design," in Proc. SPE Annual Technical Conference and Exhibition, Colorado, USA: Society of Petroleum Engineers, 2008, pp. 21-24.

[2] N. R. Warpinski and L. W. Teufel, "Influence of geologic discontinuities on hydraulic fracture propagation," J Petrol Technol, pp. 209-210, 1987.

[3] L. W. Teufel and J. C. Clark, "Hydraulic fracture propagation in layered rocks: experimental studies of fracture containment," Society of Petroleum Engineers Journal, pp. 19-34, 1984.

[4] M. Thiercelin, C. Roegiers, and T. J. Boone, "An investigation of the material parameters that govern the behavior of fracture approaching rock interfaces," Congress on Rock Mechanics, pp. 236-269, 1987.

[5] T. L. Blanton, "An experimental study of interaction between hydraulically induced and pre-existing fracturing," in Proc. SPE 10847, 1982.

[6] T. L. Blanton, "Propagation of hydraulically and dynamically induced fractures in naturally fractured reservoirs," presented at the Unconveptional Gas Technology Symposium of the Society of Petroleum Engineers, Louisville, KY, May 18-21, 1986.

[7] L. J. L. Beugelsdijk. "Experimental hydraulic fracture propagation in a multi fractured medium," in Proc. SPE 59419, 2000.
[8] C. J. de Pater and L. J. L. Beugelsdijk, "Experiments and numerical simulation of hydraulic fracturing in naturally fractured rock," presented at 40th US Symposium on Rock Mechanics, Anchorage, Alaska, June 25-29, 2005

[9] L. Casas, J. L. Miskimins, and A. Black. "Laboratory hydraulic fracturing test on a rock with artificial discontinuities," presented at the SPE Annual Technical Conference and Exhibition, San Antonio, Texas, U.S.A., 24-27 September, 2006.

[10] R. Suarez and C. Bryon, "Hydraulic fracturing experiments help understanding fracture branching on tight gas shales," ARMA/USRM06-1130, 2006.

[11] C. H. Sondergeld, K. E. Newsham, and J. T. Comisky, "Petro-physical considerations in evaluating and producing shale gas resources," in Proc. SPE Hydraulic Fracturing Technology Conference, Texas, USA: Society of Petroleum Engineers, 2010, pp. 29-31.

[12] R. Rickman, M. Mullen, and E. Petre, "A practical use of shale petro-physics for stimulation design optimization: All shale plays are not clones of the Barnettshale," in Proc. SPE Annual Technical Conference and Exhibition, Colorado, USA: Society of Petroleum Engineers, 2008, pp. 21-24.

[13] R. M. Goktan and N. G. Yilmaz, "A new methodology for the analysis of the relationship between rock brittleness index and drag pick cutting," The Journal of the South African Institute of Mining and Metallurgy, pp. 727-733, 2005.

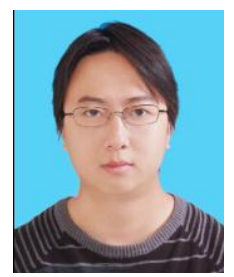

Xin Lei was born on July 8, 1984, in Gansu, China. He is a $\mathrm{PhD}$ student at China University of Petroleum, Beijing currently. He focuses on fracture propagation mechanism and fracture-oriented technology of hydraulic fracturing by radial horizontal wells, and mechanism research on hydraulic fracturing by stimulated reservoir volume for tight sandstone reservoir. 